\title{
Huperzine A attenuates hepatic ischemia reperfusion injury via anti-oxidative and anti-apoptotic pathways
}

\author{
ZHE XU and YANG WANG \\ Department of Pharmacy, Maanshan Municipal Maternal and Child Health Hospital, \\ Maanshan, Anhui 243011, P.R. China
}

Received September 11, 2013; Accepted March 12, 2014

DOI: $10.3892 / \mathrm{mmr} .2014 .2288$

\begin{abstract}
Hepatic ischemia reperfusion (HI/R) injury may occur during liver transplantation and remains a serious concern in clinical practice. Huperzine A (HupA), an alkaloid isolated from the Chinese traditional medicine Huperzia serrata, has been demonstrated to possess anti-oxidative and anti-apoptotic properties. In the present study, a rat model of $\mathrm{HI} / \mathrm{R}$ was established by clamping the hepatic artery, the hepatoportal vein and the bile duct with a vascular clamp for $30 \mathrm{~min}$ followed by reperfusion for $6 \mathrm{~h}$ under anesthesia. HupA was injected into the tail vein $5 \mathrm{~min}$ prior to the induction of $\mathrm{HI} / \mathrm{R}$ at doses of 167 and $500 \mu \mathrm{g} / \mathrm{kg}$. The histopathological assessment of the liver was performed using hematoxylin and eosin staining. Alanine aminotransferase (ALT) and aspartate aminotransferase (AST) were assayed in the serum samples. The tissue levels of superoxide dismutase (SOD), catalase (CAT), malondiadehyde (MDA) and glutathione (GSH) were also measured spectrophotometrically. Furthermore, the protein expression of caspase-3, Bcl-2 and Bax in hepatic tissues was detected via western blot analysis. Treatment of Wistar rats with HupA at doses of 167 and $500 \mu \mathrm{g} / \mathrm{kg}$ markedly attenuated HI/R injury as observed histologically. In addition, the significant reductions of serum ALT and AST were observed in HupA-treated ischemic rats. Furthermore, HupA treatment enhanced the activity of hepatic tissue SOD, CAT and GSH, but decreased the MDA tissue content. Western blot analysis revealed elevated levels of Bcl-2 expression but decreased Bax and caspase- 3 tissue expression at the protein level in the HupA-treated group. The present data suggest that HupA attenuates the HI/R injury of rats through its anti-oxidative and anti-apoptotic signaling pathways.
\end{abstract}

Correspondence to: Professor Zhe Xu, Department of Pharmacy, Maanshan Municipal Maternal and Child Health Hospital, 446 Jiashan Road, Huashan, Maanshan, Anhui 243011, P.R. China E-mail: zhexumr@163.com

Key words: huperzine A, hepatic ischemia reperfusion injury, liver, anti-oxidative, anti-apoptotic

\section{Introduction}

It is generally accepted that hepatic ischemia reperfusion injury (HI/R) is an important non-immunologic injury that may occur during circulatory shock, hepatic trauma, liver transplantation and elective liver resection (1). Severe HI/R contributes to liver failure, remote organ failure and even mortality $(2,3)$. Therefore, HI/R has always been a key concern in the development of liver surgery techniques. Several mechanisms appear to be involved in the pathophysiology of HI/R injury. It is well established that reactive oxygen species (ROS) are conceived to be a critical factor in the pathogenesis of HI/R injury. Recent studies have illustrated that excessive formation of ROS during ischemic insult not only causes the destruction of cellular structures, but also results in mitochondrial dysfunction, finally activating apoptotic cascades (4). Chandra et al (5) found that increased $\mathrm{H}_{2} \mathrm{O}_{2}$ levels in tissue may lead to apoptotic damage by upregulating the Fas-FasL system. $\mathrm{H}_{2} \mathrm{O}_{2}$ may have damaged the mitochondrial membrane, thus contributing to the release of pro-apoptotic components located in the mitochondria. The injured mitochondria activated a number of transcription factors and promoted their translocation into the nucleus, including p53 and nuclear factor (NF)- $\mathrm{kB}$. Additionally, the expression of pro-apoptotic genes may be facilitated by the suppression of ROS and survival-associated genes. By contrast, natural anti-oxidants may attenuate I/R injury. Superoxide dismutase (SOD), catalase (CAT) and glutathione (GSH) reductase treatment have effectively alleviated I/R injury in animals (6). Taking into account the fact that ischemic injury is associated with oxidation, it is important to examine the hepatoprotective agents that may ameliorate the damage of ROS in HI/R injury. Apoptosis is another important mechanism involved in HI/R injury. Kohli et al (7) identified that $50-70 \%$ of sinusoidal liver endothelial cells and $40-60 \%$ of hepatocytes underwent apoptosis.

Huperzine A (HupA), a novel alkaloid extracted from the Chinese traditional medicine, Huperzia serrate, is considered to be a drug with high clinical prospects. Previous studies have demonstrated that it has several beneficial effects for patients with Alzheimer's disease (AD) (8) and, in China it is one of the most commonly prescribed drugs for various types of dementia, including AD (9), as a result of its inhibitory effect on acetylcholinesterase (AchE). Ruan et al (10) reported that HupA markedly decreased ROS generation and oxidative 
damage in D-galactose-treated rats. Following renal I/R injury, HupA was also found to inhibit cellular apoptosis (11). These studies confirmed that HupA possessed anti-oxidative and anti-apoptotic properties. However, it remains unclear whether HupA may alleviate HI/R in rats. Therefore, the present study was conducted to assess the hepatoprotective effects against $\mathrm{H} / \mathrm{IR}$ and further examine the potential mechanisms underlying these effects.

\section{Materials and methods}

Animals and induction of $H I / R$. Male Wistar rats (weight, $240 \pm 40 \mathrm{~g}$ ) were housed in individual cages under a controlled environment (12:12 h light/dark cycle, 50-70\% humidity, $24^{\circ} \mathrm{C}$ ) and provided with free access to water and food. All of the experimental procedures were approved by the animal ethics committee of Maanshan Municipal Health Hospital For Women and Children in China (Maanshan, China). All experimental procedures were performed in a manner that minimized suffering and reduced the number of animals used.

$\mathrm{HI} / \mathrm{R}$ was induced according to the method described previously with minor modifications (11-13). Under the chloral hydrate $(200 \mathrm{mg} / \mathrm{kg})$ and ether anesthesia, rats underwent a median laparotomy. The hepatoportal vein, hepatic arterial and hepatic duct were separated, which were clamped for $30 \mathrm{~min}$ followed by a $6 \mathrm{~h}$ reperfusion with an atraumatic vascular clamp (Hengao Company of Beijing, Beijing, China). The body temperature of the animals was maintained constantly using a heating blanket during the reperfusion period. The sham group underwent all surgery with the exception of the occlusion of the hepatoportal vein, hepatic artery and hepatic duct.

Drug administration. HupA (purity, >95\%; Sigma, St. Louis, MO, USA) was dissolved in physiological saline and was injected into the tail vein 5 min prior to the induction of HI/R. The chemical structure of HupA was indicated in Fig. 1. A total of 24 rats were randomly divided into the following four groups ( $n=6$ per group): Sham, Vehicle and HupA treatment (varietal does of HupA: $167 \mu \mathrm{g} / \mathrm{kg}$ and $500 \mu \mathrm{g} / \mathrm{kg}$ ) groups. The vehicle and HupA groups underwent the HI/R procedure prior to injections with the same volume of physiological saline or HupA, respectively, through the tail veil. At the end of the reperfusion period, the rats were sacrificed by spinal dislocation and the blood and liver samples were collected. Separate tissue samples were quantified with microscopic scoring under light microscope (Nikon Corporation, Nikon, Tokyo, Japan) following hematoxylin and eosin (H\&E) staining for the histological analysis. Blood samples were drawn from the supra-hepatic vena cava by a fine needle (Trade of Antai Company, Suzhou, China) and then centrifuged at 3,000 $\mathrm{x}$ g for $5 \mathrm{~min}$ to collect the serum for the determination of the alanine aminotransferase (ALT) and aspartate aminotransferase (AST) levels. The liver tissue samples from each animal were stored at $-80^{\circ} \mathrm{C}$ for the measurement of hepatic tissue SOD, CAT, GSH and malondiadehyde (MDA) levels, together with evaluating the activity of caspase-3 and the protein expression of caspase-3, Bcl-2 and Bax.

Histological examination. The liver tissue samples were fixed in $4 \%$ paraformaldehyde (PFA) in $0.1 \mathrm{M}$ phosphate buffer ( $\mathrm{PB}$; $\mathrm{pH}$ 7.4) for $12 \mathrm{~h}$, followed by two days in $30 \%$ sucrose buffer

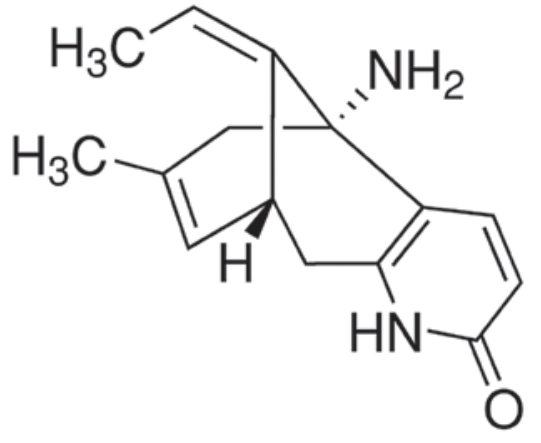

Figure 1. The chemical structure of huperzine A.

at room temperature. The serial coronal sections (6 $\mu \mathrm{m}$-thick) were obtained using a microtome and stained with H\&E and examined by light microscopy. The liver histopathological evaluation was performed in a blinded manner.

Measurement of serum ALT and AST levels. An automated autobiochemical analyzer (Toshiba, Tokyo, Japan) was employed to determine serum ALT and AST levels as described previously (12-14).

Measurement of SOD, CAT, GSH and MDA activities. The enzymatic activity of SOD, GSH, GSH-peroxidase (PX) and MDA was measured according to the manufacturer's instructions in different commercial assay kits (Nanjing Jian Cheng Bioengineering Institute, Nanjing, China).

The SOD activity in the hepatic tissue homogenate was estimated by calculating the rate of inhibition of nucleotide oxidation. The results are expressed as the U/mg protein. The CAT was assayed by quantifying flaxen complex compound, configured by ammonium molybdate and the reminder peroxide, at the wavelength of $405 \mathrm{~nm}$. The result are provided as U/mg protein. The content of GSH was assayed by quantifying the rate of oxidation of the reduced glutathione to the oxidized glutathione by $\mathrm{H}_{2} \mathrm{O}_{2}$. The results are indicated in $\mathrm{mg} \mathrm{GSH} / \mathrm{g}$ protein. The content of MDA was assayed for the products of lipid peroxidation by monitoring thiobarbituric acid reacting substances at a wavelength of $532 \mathrm{~nm}$. The level of MDA was expressed as nmol MDA/mg protein.

Western blot assay. Western blot analysis was performed on the hepatic samples. Briefly, the samples were homogenized in an ice-cold lysis buffer [10 mM Tris ( $\mathrm{pH} 8.0$ ), $150 \mathrm{mM} \mathrm{NaCl}$, $10 \%$ glycerol, $1 \%$ NP-40, 5 mM EDTA and protease inhibitor cocktail]. Following centrifugation at $13200 \mathrm{x}$ g for $20 \mathrm{~min}$ at $4^{\circ} \mathrm{C}$, the supernatant was collected and the total protein levels were quantified by a bicinchoninic protein assay kit (Beyotime Institute of Biotechnology, Shanghai, China). An equal quantity of protein $(50 \mu \mathrm{g})$ was separated by means of sodium dodecyl sulfate-polyacrylamide gel electrophoresis (SDS-PAGE) and transferred onto nitrocellulose membranes (Millipore, Billerica, MA, USA). The membranes were blocked with 5\% skimmed milk for $1 \mathrm{~h}$ at room temperature and then probed, respectively, with the following primary antibodies: Anti-caspase-3 polyclonal rabbit antibody (1:300; Cell Signaling Technology, Inc., Beverly, MA, USA), anti-Bcl-2 monoclonal rabbit antibody (1:200; Santa Cruz Biotechnology, Inc., Santa Cruz, CA, 

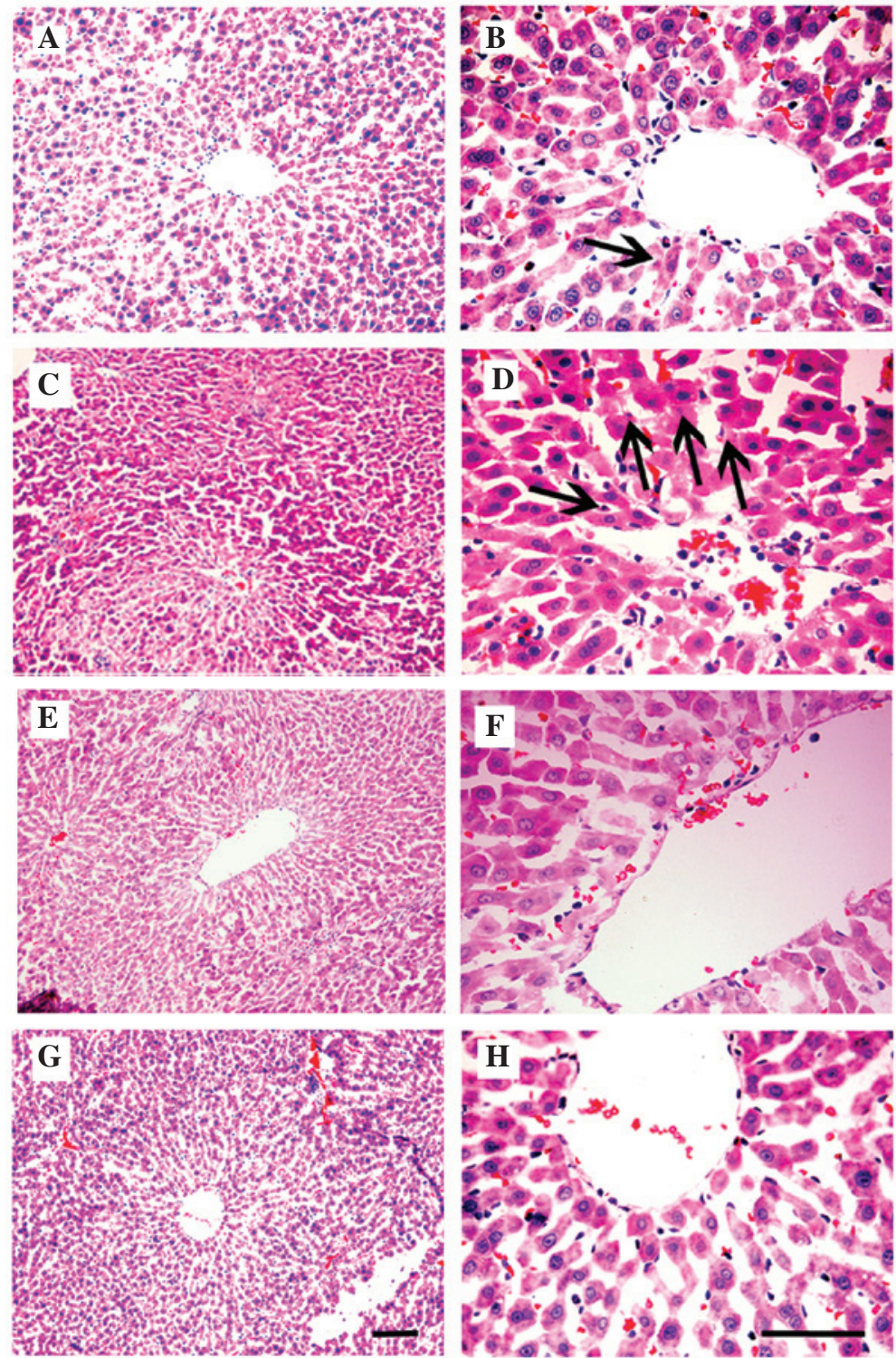

Figure 2. Effects of HupA on hepatic tissue $6 \mathrm{~h}$ following HI/R with hematoxylin and eosin staining. The representative micrographs of hepatic tissues from (A and B), sham-operated; (C and D), vehicle-treated; (E and F), HupA (167 $\mu \mathrm{g} / \mathrm{kg})$-treated and (G and $\mathrm{H})$, HupA $(500 \mu \mathrm{g} / \mathrm{kg})$-treated groups were established. Magnification, (A, C, E and G) x200; (B, D, F and H) x400. Pyknosis in the sham operated and hepatic ischemia groups is marked with arrows. Scale bar, $10 \mu \mathrm{m}$. HupA, huperzine A; HI/R, hepatic ischemia reperfusion.

USA), anti-Bax monoclonal rabbit antibody (1:200; Santa Cruz Biotechnology, Inc.) and anti- $\beta$-actin monoclonal rabbit antibody (1:2,000; Santa Cruz Biotechnology, Inc.), respectively, at $4^{\circ} \mathrm{C}$ overnight. After the membranes were washed with three changes of Tris-buffered saline with Tween-20, they were incubated for $2 \mathrm{~h}$ with peroxidase-labeled goat anti-rabbit IgG (1:5,000; Santa Cruz Biotechnology, Inc.). Immunodetection was conducted with enhanced chemiluminesecence (Applygen, Beijing, China) and exposed on an X-ray film. $\beta$-actin was used as an internal reference for relative quantification. The films were digitized by a scanner (Hewlett-Packard Development Company, Beijing, China) and the grey value of the protein bands was analyzed using Quantity One software (Bio-Rad, Hercules, CA, USA).

Assay of caspase-3 activity. The reduction in the chromogenic caspase-3 substrate acetyl-Asp-Glu-Val-Asp p-nitroanilide
(Ac-DEVD-pNA) was used to assess the activity of caspase-3. The quantity of caspase-3 was measured using a colorimetric approach with a commercial kit (Beyotime Institute of Biotechnology). The protein samples of the hepatic tissues were acquired as indicated in the western blot analysis. Approximately $50 \mu \mathrm{g}$ protein was added to a reaction buffer involvement Ac-DEVD-pNA $(2 \mathrm{mM})$, incubated at $37^{\circ} \mathrm{C}$ for $4 \mathrm{~h}$ and the absorbance of yellow pNA was calculated by a spectrometer (Shanghai CSOIF Company, Shanghai, China) at a wavelength of $405 \mathrm{~nm}$. The specific activity of caspase-3, which was normalized for the total protein in the liver was then expressed as the fold change of the baseline caspase-3 activity of the control group.

Statistical analysis. The results were expressed as the mean \pm standard deviation. Comparisons between the groups were performed by one-way analysis of variance with 
A

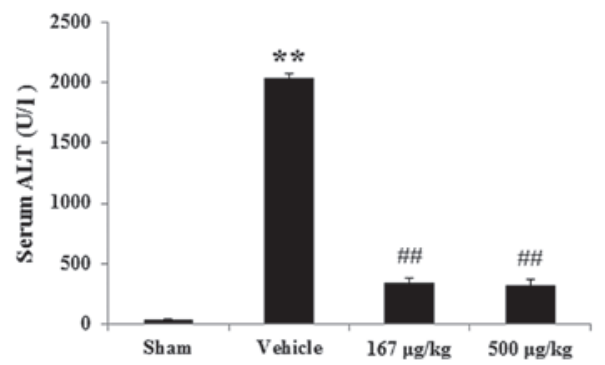

B

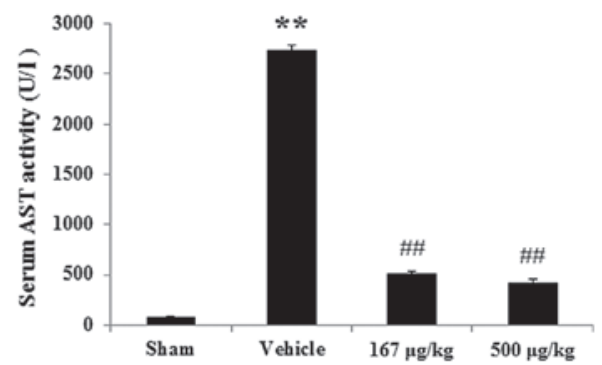

Figure 3. Effects of HupA on the levels of serum ALT and AST $6 \mathrm{~h}$ following HI/R (mean \pm standard deviation, $\mathrm{n}=6$ ). Levels of serum (A) ALT and (B) AST, respectively, in the different groups. ${ }^{* *} \mathrm{P}<0.01$ vs. sham-operated group; ${ }^{\# \#} \mathrm{P}<0.01$ vs. vehicle-treated group. Sham, sham-operated; Vehicle, vehicle-treated; $167 \mu \mathrm{g} / \mathrm{kg}$, HupA (167 $\mu \mathrm{g} / \mathrm{kg})$-treated; $500 \mu \mathrm{g} / \mathrm{kg}$, HupA (167 $\mu \mathrm{g} / \mathrm{kg})$-treated; HupA, huperzine A; ALT, alanine aminotransferase; AST, aspartate aminotransferase.

A

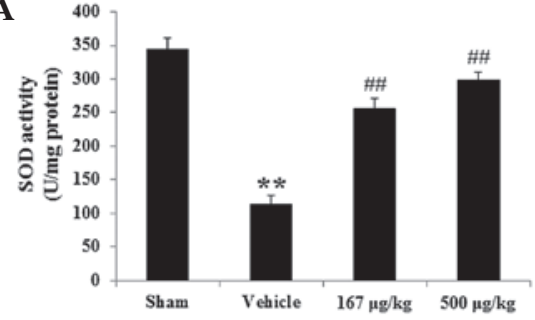

C

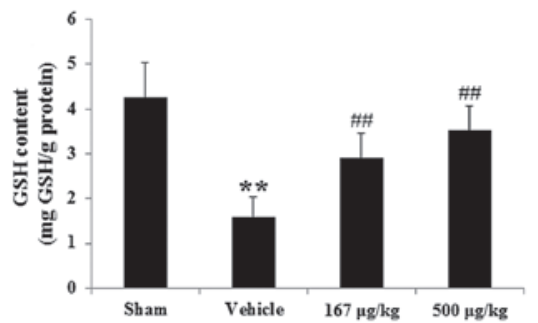

B

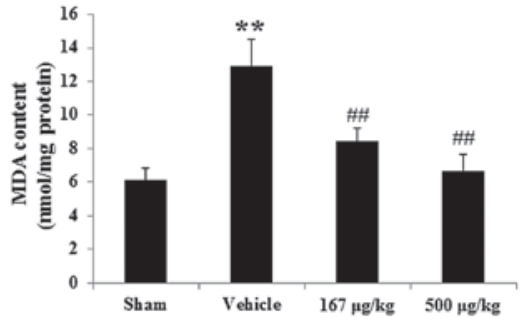

D

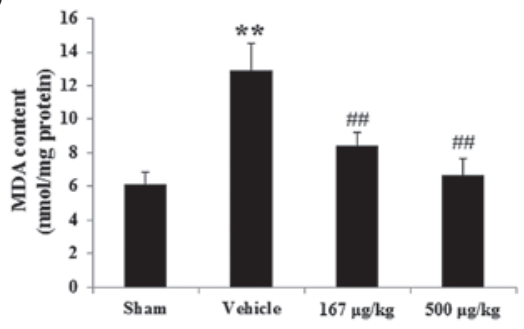

Figure 4. Effects of HupA on the activity of antioxidant enzymes (SOD, CAT) and the contents of GSH and MDA in hepatic tissues $6 \mathrm{~h}$ following HI/R (mean \pm standard deviation, $n=6$ ). The graphs show the activity of (A) SOD, (B) CAT and the contents of (C) GSH and (D) MDA, respectively, in the different groups. * $<<0.01$ vs. the sham-operated group; ${ }^{\# \#} \mathrm{P}<0.01$ vs. vehicle-treated group. Sham, sham-operated; Vehicle, vehicle-treated; $167 \mu \mathrm{g} / \mathrm{kg}, \mathrm{HupA}(167 \mu \mathrm{g} / \mathrm{kg})$-treated; $500 \mu \mathrm{g} / \mathrm{kg}$, HupA (167 $\mu \mathrm{g} / \mathrm{kg})$-treated; HupA, huperzine A; SOD, superoxide dismutase; CAT, catalase; GSH, glutathione; MDA, malondiadehyde.

Dunnett's test using SPSS 13.0 software (SPPS, Inc., Chicago, IL, USA). $\mathrm{P}<0.05$ was considered to indicate a statistically significant difference.

\section{Results}

Histopathological examination. As demonstrated in Fig. 2A and $\mathrm{B}$, the sham group exhibited normal liver cellular structure. As observed in Fig. 2C and D, the vehicle group exhibited a mass of hepatocytes cytoplasmic color fading and nuclear condensation. When the ischemic rats were treated with HupA at the doses of 167 and $500 \mu \mathrm{g} / \mathrm{kg}$, it was noted that the cytoplasmic color fading and nuclear condensation of the hepatocytes were significantly diminished, as illustrated in Fig. 2E-H.

Serum ALT and AST levels. In the physiological saline-treated HI/R group, the levels of serum ALT, which was the marker of hepatic damage, were significantly increased (Fig. 3A) from 36.10 \pm 8.37 to $2034.77 \pm 45.84 \mathrm{U} / 1(\mathrm{P}<0.01$, $\mathrm{n}=6$ ) compared with the sham group. However, the HupA groups (167 and $500 \mu \mathrm{g} / \mathrm{kg}$ ) markedly reduced the ALT level from $2034.77 \pm 45.84$ to $342.92 \pm 38.64(\mathrm{P}<0.01, \mathrm{n}=6)$ and
319.53 $\pm 50.05 \mathrm{U} / 1(\mathrm{P}<0.01, \mathrm{n}=6)$, respectively, compared with the HI/R group. Similarly, the levels of serum AST of the vehicle group were notably enhanced compared with the sham group (Fig. 3B) from $72.77 \pm 11.83$ to $2738.10 \pm 43.23 \mathrm{U} / 1(\mathrm{P}<0.01$, $\mathrm{n}=6$ ). However the AST levels in the HupA groups (167 and $500 \mu \mathrm{g} / \mathrm{kg}$ ) were markedly decreased from $2738.10 \pm 43.23$ to 507.92 $\pm 23.40(\mathrm{P}<0.01, \mathrm{n}=6)$ and 422.86 $\pm 38.71 \mathrm{U} / 1(\mathrm{P}<0.01$, $\mathrm{n}=6$ ), respectively compared with the vehicle group.

Activity of anti-oxidative enzymes (SOD and CAT) and the levels of MDA and GSH in hepatic tissue. In order to examine the effects of HupA on oxidative stress during HI/R injury in rats, the activity of anti-oxidative enzymes (SOD and CAT) and the levels of GSH and MDA in hepatic tissue were investigated in the present study. Fig. 4A demonstrates that the activity of SOD, one of the most important anti-oxidative enzymes, was significantly reduced in the vehicle group from $344.44 \pm 17.41$ to $113.10 \pm 14.14 \mathrm{U} / \mathrm{mg}$ protein compared with the sham group $(\mathrm{P}<0.01, \mathrm{n}=6)$. Following administration of HupA (167 and $500 \mu \mathrm{g} / \mathrm{kg})$, the activity of SOD was significantly enhanced from $113.10 \pm 14.14$ in the HI/R group to $256.25 \pm 15.19(\mathrm{P}<0.01$, $\mathrm{n}=6)$ and $297.86 \pm 12.14 \mathrm{U} / \mathrm{mg}$ protein $(\mathrm{P}<0.01, \mathrm{n}=6)$ in the 167 
A

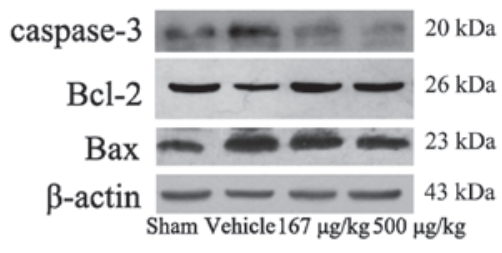

B

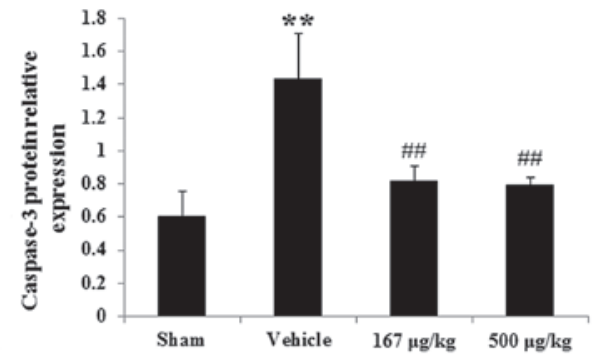

C

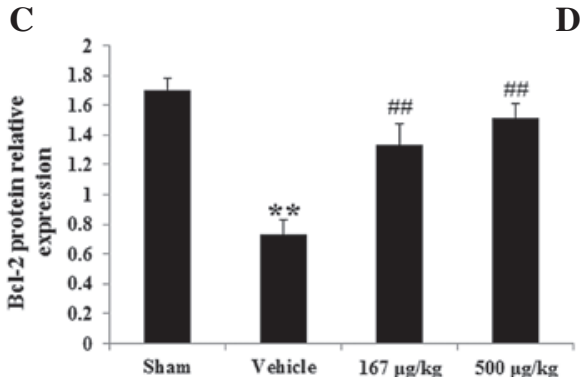

D

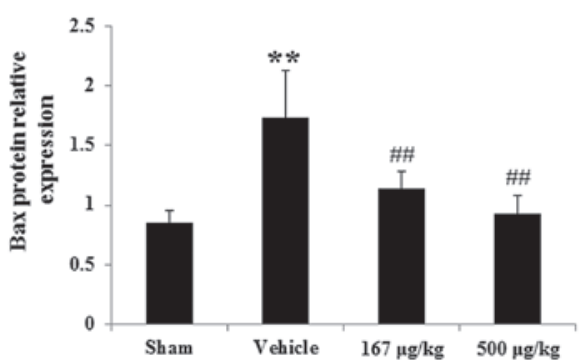

Figure 5. Effects of HupA on the protein expression of caspase-3, Bcl-2 and Bax in hepatic tissues $6 \mathrm{~h}$ following HI/R (mean \pm standard deviation, $\mathrm{n}=6$ ). (A) Representative images of immunoblots for caspase-3, Bcl-2 and Bax in the different groups. The quantitative analysis of the protein levels of (B) caspase-3, (C) Bcl-2 and (D) Bax in the different groups, respectively. The data were normalized to the loading control $\beta$-actin. ${ }^{* *} \mathrm{P}<0.01 \mathrm{vs}$. the sham-operated group; ${ }^{\# \#} \mathrm{P}<0.01$ vs. the vehicle-treated group. Sham, sham-operated; Vehicle, vehicle-treated; $167 \mu \mathrm{g} / \mathrm{kg}, \mathrm{HupA}(167 \mu \mathrm{g} / \mathrm{kg})$-treated; $500 \mu \mathrm{g} / \mathrm{kg}, \mathrm{HupA}$ $(167 \mu \mathrm{g} / \mathrm{kg})$-treated; HupA, huperzine A; HI/R, hepatic ischemia reperfusion.

and $500 \mu \mathrm{g} / \mathrm{kg}$ HupA groups, respectively. Similarly, the activity of CAT in the vehicle group was also decreased compared with the sham group from $39.10 \pm 7.58(\mathrm{P}<0.01, \mathrm{n}=6)$ to $15.77 \pm 5.87 \mathrm{U} /$ mg protein $(\mathrm{P}<0.01, \mathrm{n}=6)$. Notably, following treatment with HupA at the doses of 167 and $500 \mu \mathrm{g} / \mathrm{kg}$, the activity of CAT was enhanced from $15.77 \pm 5.87$ in the ischemic group to $30.75 \pm 6.31$ $(\mathrm{P}<0.01, \mathrm{n}=6)$ and $37.03 \pm 6.82 \mathrm{U} / \mathrm{mg}$ protein $(\mathrm{P}<0.01, \mathrm{n}=6)$ respectively (Fig. 4B). As revealed in Fig. 4C, the quantity of GSH in the vehicle group markedly reduced to $1.60 \pm 0.43 \mathrm{mg} / \mathrm{g}$ protein compared with the sham group $(4.27 \pm 0.76, \mathrm{P}<0.01, \mathrm{n}=6)$. Following treatment with HupA at doses of 167 and $500 \mu \mathrm{g} / \mathrm{kg}$, the content of GSH was increased to $2.92 \pm 0.53(\mathrm{P}<0.01, \mathrm{n}=6)$ and $3.53 \pm 0.53(\mathrm{P}<0.01, \mathrm{n}=6)$, respectively. Additionally, the content of MDA (Fig. 4D), a marker of lipid peroxidation, in the vehicle group was significantly increased in the hepatic tissue from $6.10 \pm 0.76$ to $12.93 \pm 1.58 \mathrm{nmol} / \mathrm{mg}$ protein $(\mathrm{P}<0.01, \mathrm{n}=6)$, compared with the sham group. A marked reduction in the MDA level was observed in the HupA-treated (167 and $500 \mu \mathrm{g} / \mathrm{kg}$ ) rats from $12.93 \pm 1.58$ in the vehicle-treated ischemic rats to $8.42 \pm 0.78$ and $6.70 \pm 0.98 \mathrm{nmol} / \mathrm{mg}$ protein $(\mathrm{P}<0.01, \mathrm{n}=6)$, respectively.

Protein expression of Bcl-2, Bax and caspase-3. Western blot analysis was further performed to examine the effect of HupA on the expression of apoptosis-regulatory proteins, including caspase-3, Bcl-2 and Bax in hepatic tissues. Fig. 5A demonstrates the western blotting results with antibodies specific to caspase-3, Bcl-2 and Bax. The protein expression of caspase- 3 in ischemic rats hepatic tissues was significantly elevated from $0.60 \pm 0.15$ to $1.43 \pm 0.27(\mathrm{P}<0.01, \mathrm{n}=6)$ compared with that in the sham group. However, when treated with HupA (167 and $500 \mu \mathrm{g} / \mathrm{kg}$ ), the caspase-3 protein level was markedly reduced to $0.82 \pm 0.08(\mathrm{P}<0.01, \mathrm{n}=6)$ and $0.80 \pm 0.05(\mathrm{P}<0.01, \mathrm{n}=6)$, respectively, compared with the vehicle-treated group, as demonstrated in Fig. 5B. The protein expression of Bcl-2 in the hepatic tissue of the vehicle group was markedly reduced from $1.70 \pm 0.08$ to

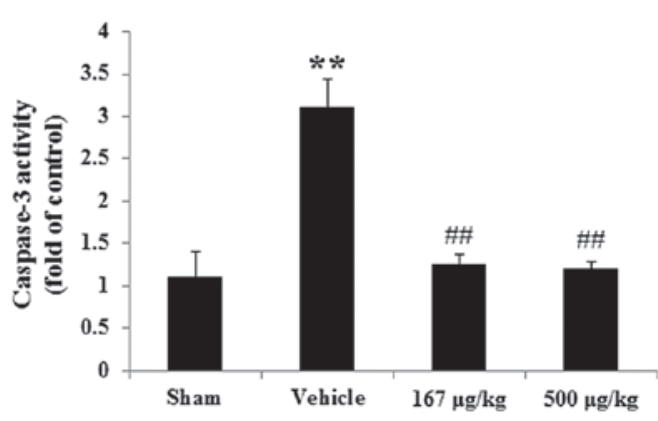

Figure 6. Effects of HupA on the caspase-3 activity in hepatic tissues $6 \mathrm{~h}$ following HI/R (mean \pm standard deviation, $\mathrm{n}=6$ ). ${ }^{* *} \mathrm{P}<0.01$ vs. the sham-operated group; ${ }^{\# \prime} \mathrm{P}<0.01$ vs. the vehicle-treated group. Sham, sham-operated; Vehicle, vehicle-treated; $167 \mu \mathrm{g} / \mathrm{kg}$, HupA (167 $\mu \mathrm{g} / \mathrm{kg})$-treated; $500 \mu \mathrm{g} / \mathrm{kg}$, HupA $(167 \mu \mathrm{g} / \mathrm{kg})$-treated; HupA, huperzine A; HI/R, hepatic ischemia reperfusion.

$0.73 \pm 0.10(\mathrm{P}<0.01, \mathrm{n}=6)$ compared with the sham group. HupA treatment at doses of 167 and $500 \mu \mathrm{g} / \mathrm{kg}$ caused a marked elevation in the $\mathrm{Bcl}-2$ protein expression level from $0.73 \pm 0.10$ to $1.33 \pm 0.15(\mathrm{P}<0.01, \mathrm{n}=6)$ and $1.51 \pm 0.09(\mathrm{P}<0.01, \mathrm{n}=6)$ compared with the vehicle group (Fig. 5C). Additionally, in the vehicle group, the protein expression of Bax was significantly increased from $0.85 \pm 0.09$ to $1.73 \pm 0.39(\mathrm{P}<0.01, \mathrm{n}=6)$ compared with the sham group. However, the protein level of Bax was markedly decreased to $0.97 \pm 0.07(\mathrm{P}<0.01, \mathrm{n}=6)$ and $0.94 \pm 0.03(\mathrm{P}<0.01$, $\mathrm{n}=6$ ), respectively, following treatment with HupA at doses of 167 and $500 \mu \mathrm{g} / \mathrm{kg}$, compared with the vehicle group (Fig. 5D).

Caspase-3 activity. To identify whether HupA was able to suppress caspase-3 activity, a colorimetric analysis was performed. As revealed in Fig. 6, caspase-3 activity in the vehicle group was markedly enhanced by $181.82 \% \quad(\mathrm{P}<0.01$, $\mathrm{n}=6)$, compared with the sham group. In the HupA treatment (167 and $500 \mu \mathrm{g} / \mathrm{kg}$ ) groups, there was an evident reduction in 
caspase-3 activity by $59.68 \%(\mathrm{P}<0.01, \mathrm{n}=6)$ and $61.29 \%(\mathrm{P}<0.01$, $\mathrm{n}=6$ ), respectively, compared with that in the vehicle group.

\section{Discussion}

HupA is an alkaloid isolated from the Chinese herb Huperzia serrate, and has been widely used as a selective inhibitor of AchE to treat $\mathrm{AD}$ and vascular dementia in China. As well as inhibiting AchE, HupA was also reported to have neuroprotective effects against cerebral ischemic injury (15). Recently, Wang et al (16). demonstrated that HupA inhibited the overexpression of proinflammatory enzymes induced by oxygen-glucose deprivation in C6 rat glioma cells, partly through activation of a cholinergic anti-inflammatory pathway In addition, a previous investigation demonstrated that HupA was able to diminish the excessive production of ROS following middle cerebral artery occlusion in rats (4). However, to the best of our knowledge, there is no evidence of the protective effects of HupA against hepatic warm I/R injury. It was hypothesized that the administration of HupA may reduce HI/R. To the best of our knowledge, the present study demonstrated for the first time, that HupA exerted protection from HI/R injury and this hepatoprotective effect may be associated with its anti-oxidative and anti-apoptotic properties.

It is well established that the accumulation of ROS is closely correlated with the pathogenesis of HI/R injury $(17,18)$. Enhanced hepatic anti-oxidative ability reduces the damage induced by ischemia reperfusion. A previous study demonstrated that mice overexpressing SOD and CAT exhibited significant improvements following HI/R injury compared with the normal mice (6). In another study, intravenous administration of GSH protected hepatocytes and improved animal survival following HI/R (19). The MDA level, a biomarker for evaluating the severity of reperfusion injury, is evidently increased during ischemia reperfusion. Under physiological condition, ROS levels are rapidly detoxified by endogenous anti-oxidative enzymes and low-molecular weight anti-oxidants, including SOD, CAT and GSH. In the present study, the SOD and CAT activity as well as the GSH content were markedly higher following the treatment with HupA compared with that in the ischemic rats, but the content of MDA was significantly lower. The present results indicated that HupA alleviated HI/R injury, at least, partly through its anti-oxidative activity.

Hepatic damage following ischemic injury occurs via oxidative stress and/or mitochondrial dysfunction, and ultimately activates an apoptotic cascade. It is well established that caspases are a family of cystein-dependent proteases with a critical role in the initiation and execution of cellular apoptosis. Caspases are specifically activated by apoptotic stimuli and caspase- 3 is conceived as an executioner of apoptosis (20). Cumulative evidence has supported the hypothesis that caspase- 3 expression is upregulated following hepatic ischemia. In addition to caspases, $\mathrm{Bcl}-2$ family proteins have also been demonstrated to exhibit a critical role in the modulation of neuronal apoptosis. Bcl-2 itself acts as an anti-apoptotic protein, whereas another member of the family, Bax, functions as a pro-apoptotic molecule (21). The present study demonstrated that HupA markedly decreased the protein expression levels of caspase- 3 and Bax, and elevated Bcl-2 in rats induced by HI/R injury. Consistent with these data, HupA was also found to inhibit cellular apoptosis following renal I/R injury (11), suggesting that enhanced the therapeutic effect of HupA may also be associated with its anti-apoptotic action in ischemic rats.

In conclusion, the present study demonstrated that HupA attenuated HI/R injury by minimizing oxidative stress and decreasing the expression of apoptosis-associated proteins, including caspase-3, Bcl-2 and Bax. Therefore it was concluded that the hepatoprotective effect of HupA may be associated with its anti-oxidative and anti-apoptotic properties in HI/R injury in rats.

\section{References}

1. Bayramoglu G, Bayramoglu A, Engur S, Senturk H, Ozturk N and Colak S: The hepatoprotective effects of Hypericum perforatum $\mathrm{L}$. on hepatic ischemia/reperfusion injury in rats. Cytotechnology Jun 23, 2013 (Epub ahead of print).

2. Liu DL, Jeppsson B, Hakansson $\mathrm{CH}$ and Odselius R: Multiple-system organ damage resulting from prolonged hepatic inflow interruption. Arch Surg 131: 442-447, 1996.

3. Çekın AH, Gür G, Türkoğlu S, et al: The protective effect of L-carnitine on hepatic ischemia-reperfusion injury in rats. Turk $\mathrm{J}$ Gastroenterol 24: 51-56, 2013.

4. Chan PH: Mitochondria and neuronal death/survival signaling pathways in cerebral ischemia. Neurochem Res 29: 1943-1949, 2004.

5. Chandra J, Samali A and Orrenius S: Triggering and modulation of apoptosis by oxidative stress. Free Radic Biol Med 29: 323-333, 2000.

6. He SQ, Zhang YH, Venugopal SK, et al: Delivery of antioxidative enzyme genes protects against ischemia/reperfusion-induced liver injury in mice. Liver Transpl 12: 1869-1879, 2006.

7. Kohli V, Selzner M, Madden JF, Bentley RC and Clavien PA: Endothelial cell and hepatocyte deaths occur by apoptosis after ischemia-reperfusion injury in the rat liver. Transplantation 67: 1099-1105, 1999.

8. Wang R, Yan H and Tang XC: Progress in studies of huperzine A, a natural cholinesterase inhibitor from Chinese herbal medicine. Acta Pharmacol Sin 27: 1-26, 2006.

9. Zhang HY, Zheng CY, Yan H, et al: Potential therapeutic targets of huperzine A for Alzheimer's disease and vascular dementia. Chem Biol Interact 175: 396-402, 2008.

10. Ruan Q, Liu F, Gao Z, et al: The anti-inflamm-aging and hepatoprotective effects of huperzine A in D-galactose-treated rats. Mech Ageing Dev 134: 89-97, 2013.

11. Ye W, Gong X, Xie J, et al: AChE deficiency or inhibition decreases apoptosis and p53 expression and protects renal function after ischemia/reperfusion. Apoptosis 15: 474-487, 2010.

12. Zhang F, Mao Y, Qiao H, et al: Protective effects of taurine against endotoxin-induced acute liver injury after hepatic ischemia reperfusion. Amino Acids 38: 237-245, 2010.

13. Jiang H, Meng F, Li W, Tong L, Qiao H and Sun X: Splenectomy ameliorates acute multiple organ damage induced by liver warm ischemia reperfusion in rats. Surgery 141: 32-40, 2007.

14. Gillissen A, Bartling A, Schoen S and Schultze-Werninghaus G: Antioxidant function of ambroxol in mononuclear and polymorphonuclear cells in vitro. Lung 175: 235-242, 1997.

15. Zhou J,Zhang HY and Tang XC: Huperzine A attenuates cognitive deficits and hippocampal neuronal damage after transient global ischemia in gerbils. Neurosci Lett 313: 137-140, 2001.

16. Wang ZF and Tang XC: Huperzine A protects C6 rat glioma cells against oxygen-glucose deprivation-induced injury. FEBS Lett 581: 596-602, 2007.

17. Kang KJ: Mechanism of hepatic ischemia/reperfusion injury and protection against reperfusion injury. Transplant Proc 34: 2659-2661, 2002.

18. Teoh NC and Farrell GC: Hepatic ischemia reperfusion injury: pathogenic mechanisms and basis for hepatoprotection. J Gastroenterol Hepatol 18: 891-902, 2003.

19. Schauer RJ, Gerbes AL, Vonier D, et al: Glutathione protects the rat liver against reperfusion injury after prolonged warm ischemia. Ann Surg 239: 220-231, 2004.

20. Perry DK, Smyth MJ, Stennicke HR, et al: Zinc is a potent inhibitor of the apoptotic protease, caspase-3. A novel target for zinc in the inhibition of apoptosis. J Biol Chem 272: 18530-18533, 1997.

21. Jin S and Dai CL: Attenuation of reperfusion-induced hepatocyte apoptosis is associated with reversed bcl-2/bax ratio in hemi-hepatic artery-preserved portal occlusion. J Surg Res 174: 298-304, 2012. 